\title{
The Role of Psychological Well-being on University EFL Learners' Attributional Patterns
}

\author{
Azar Hosseini Fatemi \\ English Department, Ferdowsi University of Mashhad \\ PO box 9177948974, Park Square, Ferdowsi University, Mashhad, Iran \\ E-mail: azar.h.fatemi@ferdowsi.ac.ir \\ Arezoo Asghari \\ English Department, Ferdowsi University of Mashhad \\ PO box 9177948974, Park Square, Ferdowsi University, Mashhad, Iran \\ E-mail: arezoo.asghari@yahoo.com
}

\section{Doi:10.5901/jesr.2016.v6n1p189}

\begin{abstract}
The aim of this study was to investigate the relationship between learners' state of psychological well-being and their attributional patterns in learning English as a foreign language. The sample consists of 96 university students studying English literature and language teaching in Ferdowsi University of Mashad, 42 of whom were male and 54 female whose age ranged from18 to 26 years old. The participants completed Attribution Theory for Foreign Language Learners Questionnaire and Ryff Scale of Psychological Well-being in one session. The correlational study indicated positive and significant correlations between psychological well-being subscales and all the attribution patterns except for the association between Personal growth and Language policy which was non-significant. The results of regression analyses demonstrated that some of psychological well-being subscales could predict some of the factors learners ascribe their success or failure to.
\end{abstract}

Keywords: psychological well-being, Ryff Scale of Psychological Well-being, Attribution Theory, Attribution Theory for Foreign Language Learners Questionnaire

\section{Introduction}

In the domains of motivation, social psychology, and educational psychology attribution theory has been considered as a dominant concept with a powerful empirical support (Weiner, 2000). Attribution theory mostly deals with people's explanations of their successes or failures (Weiner, 1974). They ask why questions and they look for an answer (Weiner $\&$ Craighead, 2010). There is a wide range of answers to these questions due to various factors. One of these factors which is more individualistic is the psychological well-being of individuals. In the process of learning students are involved in different contexts and situations. Based on their successes and failures, they investigate a reason for their outcomes.

The term well-being is a multifaceted and dynamic concept that covers social, subjective, health-related behaviors and psychological aspects. Psychological well-being (PWB) is defined as "well-being could be related to the quality of life, however defined, or to life satisfaction, however defined" (Brown, 1992, p.186). According to Ryff (1989) many scholars have referred to psychological well-being with its six criteria of autonomy, personal growth, environmental mastery, positive relations with others, purpose in life, and self-acceptance.

Therefore, each learner with his own understanding of himself and environment, his own purpose and relations would attribute his success or failure to a certain factor. Language learners might encounter these interpretations and explanations of passing or failing a foreign language more than other fields of study. Learners' awareness of attributional factors and their level of psychological well-being might give them a deeper insight for learning and more future chances for success. Moreover, language teachers can guide the learners in their challenging learning situations. There is no study, to the knowledge of the researchers, in this area. Therefore, this paper has been aimed at investigating the attribution theory and its relationship with language learners' psychological well-being. 


\section{Theoretical Background}

\subsection{Attribution Theory}

In the world of learning, learners actively attempt to understand and interpret their position (White, 1959; Williams \& Burden, 1997). In this world, learners form beliefs based on the results they achieve which directly affect their action, motivation and achievement (Bandura, 1977). Weiner's attribution theory has substantially contributed to students' motivation to learn (Hsieh, 2012). Heider (1958), who is acknowledged to be the founder of this theory, introduced the personal and environmental factors as the perceived cause of behavior. Based on this theory Rotter (1966) proposed locus of control which concerned with the fact that the individual considers the cause of an event as internal or external. Weiner's model (1976), which is the most comprehensive one, has categorized attributions into three dimensions of locus, stability and controllability. Locus concerns with whether the cause is external or internal to the individual. Stability deals with whether the cause is stable or unstable and controllability refers to how much control the individual believes he has over a cause. Various studies have shown that different individuals attribute to different individual factors such as their culture, age and gender (e.g. William, Burden, Poulet, \& Maun, 2004; Beyer, 1998 \& 1999; Hossein Fatemi \& Asghari, 2012; Meece, Glienke \& Burg, 2006).

Attribution theory has been investigated in different areas, however, little research has been done in the domain of language learning (Williams, Burden, Poulet, \& Maun, 2004). Williams, Burden, and Al-Baharna (2001) in their research, which focused on school children's attributions in learning English, highlighted the important role of attribution in learners' motivation and investigated the function of learners' cultural background such as family. Lim (2007) conducted a research on the effects of attributions and task values on foreign language use anxiety. Pishghadam and Modarresi (2008) constructed and validated a questionnaire to investigate the factors English language learners attribute their successes and failures to. Hsieh and Schallert (2008) administered a questionnaire, attributional dimension measure, and a selfefficacy measure to language learners. Pishghadam and Zabihi (2011) investigated the relationship between EFL learners' attributions in foreign language learning and their achievement in language classes. Wu (2011) investigated students' attribution preferences and gender difference in learning English. Pishghadam and Motakef (2011) studied attributions of high school students, majoring in different fields, in learning a foreign language. Hosseini Fatemi, Pishghadam, and Asghari (2012) investigated the relationship between EFL learners' attributional patterns and their personality traits. While in another similar study, Hosseini Fatemi and Asghari (2012) studied the association between learners' personality traits and their sets of attributions in learning English as a foreign language, regarding their gender differences. The mentioned studies show that although attribution theory has been under investigation, it needs to be further established what qualities the language learners possess that lead them to attributing to certain factors as these attributions can determine their future achievements.

\subsection{Psychological well-being}

Well-being at the psychological level can be defined in various ways; however, the common attributions are namely, selfefficacy, sense of control, self-determination, environmental mastery, optimism, an orientation towards personal and psychological growth, and involvement in meaningful pursuits. This term is mostly defined as the presence of positive affect and lack of negative affect (Prilleltensky, \& Prilleltensky, 2006). A vital part of psychological well-being is the selfconcept which explains that if an individual had a positive feeling about himself and his abilities, he would be more efficient. Self-concept facilitates some conceptions such as motivation, happiness, anxiety, and depression (Craven \& Marsh, 2008). Researches have indicated a relationship between self-concept and academic achievement (Marsh \& Craven, 2006). Erikson (1963) believes that identity is formed successfully in an individual when he is psychologically well. Moreover, according to Jones (2002), the degree of adolescence's engagement in a search of meaning is related to his state of psychological well-being.

Although psychological well-being has been under research in different domains, there is a gap in the field of language learning. Therefore, the empirical studies reviewed here are not related to foreign language learning. Ryff and Keyes (1995) tested the six dimensional model of psychological well-being and the confirmatory factor analysis supported the model. Van Dierendonck (2004) in his study investigated the Ryff's scale of psychological well-being and examined its factorial and content validity. Zapf (2002) had done a literature review on emotion work with an emphasis on its influence on psychological well-being. O' Reilley, Ryan and Hickey (2010) used the measures of stress, loneliness, psychological well-being, social support, and socio-cultural adaptation in his study. Liebkind and Jasisnskaja-Lahti (2000) 
worked on the relationship between acculturation and psychological well-being of immigrant adolescents. Vleioras and Bosma (2005) used the Identity Style Inventory and the scales of psychological well-being in an academic environment. Parto and Besharat (2011) studied the association among mindfulness, psychological well-being and psychological distress. Lavasani, Borhanzadeh, Afzali and Hejazi (2011) did their study to examine the relationship among perceived parenting styles, social support and psychological well-being. Sedaghat, Mohammadi, Alizadeh, and Imani (2011) investigated an Iranian sample to study effects of mindfulness-based stress reduction on the enhancement of mindfulness, psychological and emotional well-being and the reduction of stress. In their study, Souri and Hasanirad (2011) examined the association among resilience, optimism and psychological well-being.

Despite all the attempts in applying psychological well-being, to the best knowledge of the researchers, there is no study investigating the effect of this psychological factor on the process of language learning. Therefore, this study is in search of the probable effect of language learners' psychological well-being on their successes or failures in learning English as a foreign language. In case this relationship is confirmed, it can make the language teachers conscious of an aspect of individual difference in language learners which has a role in determining their success or failure of future achievements.

\section{Research question}

Based on the gaps in the previous studies and few numbers of researches that have investigated attribution theory in the field of language learning, and the important role of this theory (Dörnyei, 2005), it needs to be further established what qualities the language learners possess that lead them to ascribing to different attributional factors. The present study will be an attempt to explore the answer to the following questions:

Q1: Is there any significant relationship between university EFL learners' level of psychological well-being and their attributional patterns?

Q2: Can EFL learners' psychological well-being predict their attributional factors?

\section{Method}

\subsection{Participants}

The participants were 96 university students studying English literature and language teaching in Ferdowsi University of Mashad, 42 of whom were male and 54 female whose age ranged from 18 to 26 years old. For this study EFL university students were chosen as they have enough experience in language learning; therefore, they are more capable of giving their views on the factors that cause their success or failure in their learning process.

\subsection{Instruments}

For collecting the data, researchers applied two questionnaires: Ryff Scale of Psychological Well-being and Attribution Theory for Foreign Language Learners Questionnaire

\subsubsection{Ryff Scale of Psychological Well-being}

To find out about the psychological well-being of learners the Ryff Scale of Psychological Well-being is going to be administered. This scale is considered as the best instrument for measuring psychological well-being objectively (Conway \& Maclead, 2002). This inventory consists of three forms: long, medium, and short form. All are checking the six areas of psychological well-being which are namely: autonomy, personal growth, environmental mastery, positive relations with others, purpose in life, and self-acceptance. In this study the Persian version of the long form which consists of 84 questions is going to be used. The reported alpha was .80 .

\subsubsection{Attribution Theory for Foreign Language Learners Questionnaire}

The other instrument is the ATFLL questionnaire which is checking the four attributional factors of emotions, self-image, intrinsic motivation, and language policy. This questionnaire was designed and validated by Pishghadam and Modaressi (2008) which was constructed based on Weiner's (1979) suggestion of four factors of ability, effort, luck, and task 
difficulty. This Persian questionnaire has 30 items in the 5-point Likert type scale. The reported reliability was 0.84 .

\subsection{Procedure}

The data were collected in June, 2013. Ninety six language learners were given the two questionnaires (Attribution Theory for Foreign Language Learners Questionnaire and Ryff Scale of Psychological Well-being). The participants answered the 30-item ATFLL questionnaire and 84-item Ryff Scale of Psychological Well-being questionnaire in one session. It took about 40 minutes for the respondents to answer all the questions.

After collecting the data, it was entered and processed with SPSS 18 program. First the reliability of both questionnaires was measured. The Pearson product moment formula was used to calculate the correlation between learners' psychological well-being and attributional factors. Multiple regression analysis was also used to see which psychological factors were better predictors of the factors to which learners attributed for their success and failure.

\section{Results}

To analyze the data, SPSS 18 was used. Descriptive statistics including minimum, maximum, mean, standard deviation, skewness, and kurtosis are reported in Table 1. As this Table indicates, the skewness and kurtosis indices are within the range of -2 and +2 , which shows the normal distribution of the data.

Table 1. Descriptive Statistics

\begin{tabular}{|l|c|c|c|c|c|c|c|c|c|}
\hline & $\mathrm{N}$ & Minimum & Maximum & Mean & Std. Deviation & \multicolumn{2}{|c|}{ Skewness } & \multicolumn{2}{c|}{ Kurtosis } \\
\cline { 2 - 11 } & Statistic & Statistic & Statistic & Statistic & Statistic & Statistic & Std. Error & Statistic & Std. Error \\
\hline Emotion & 92 & 10.00 & 40.00 & 23.0978 & 6.96468 & .502 & .251 & -.056 & .498 \\
\hline Self.image & 92 & 25.00 & 55.00 & 42.3043 & 7.05199 & -.250 & .251 & -.345 & .498 \\
\hline Intrinsic.motivation & 92 & 12.00 & 29.00 & 22.4565 & 2.98499 & -.283 & .251 & .586 & .498 \\
\hline Language.policy & 92 & 6.00 & 20.00 & 13.4348 & 2.41926 & -.035 & .251 & .503 & .498 \\
\hline Environmental.mastery & 92 & 20.00 & 54.00 & 37.1848 & 5.44892 & -.117 & .251 & .976 & .498 \\
\hline Personal.growth & 92 & 26.00 & 49.00 & 37.0870 & 4.42185 & .012 & .251 & -.220 & .498 \\
\hline Purpose.in.life & 92 & 26.00 & 54.00 & 36.0217 & 5.70324 & .601 & .251 & .513 & .498 \\
\hline Selfacceptance & 92 & 27.00 & 51.00 & 36.2391 & 4.87282 & .581 & .251 & .321 & .498 \\
\hline Positive.relation & 92 & 25.00 & 53.00 & 38.2935 & 5.37912 & .071 & .251 & -.031 & .498 \\
\hline Autonomy & 92 & 28.00 & 52.00 & 40.3804 & 5.05756 & -.325 & .251 & -.187 & .498 \\
\hline Valid N (listwise) & 92 & & & & & & & & \\
\hline
\end{tabular}

To answer the first research question, Pearson Product-Moment Correlation Formula was used to examine the possible correlations between psychological well-being subscales and attribution patterns. The results of the correlation analyses are summarized in Table 2.

Table 2. Correlations between Psychological Well-being and Attribution

\begin{tabular}{|c|c|c|c|c|}
\hline & Emotion & Self-image & Intrinsic Mot & Language policy \\
\hline Environmental mastery & $.51^{\star \star}$ & $.42^{\star \star}$ & $.35^{\star \star}$ & $.21^{*}$ \\
\hline Personal growth & $.32^{\star \star}$ & $.28^{\star \star}$ & $.27^{\star \star}$ & .10 \\
\hline Purpose in life & $.38^{\star \star}$ & $.41^{\star \star}$ & $.41^{\star \star}$ & $.23^{*}$ \\
\hline Self-acceptance & $.28^{\star \star}$ & $.32^{\star \star}$ & $.34^{\star \star}$ & $.23^{\star}$ \\
\hline Positive relation & $.41^{\star *}$ & $.43^{\star *}$ & $.38^{\star \star}$ & $.25^{*}$ \\
\hline Autonomy & $.34^{\star \star}$ & $.44^{\star \star}$ & $.53^{\star \star}$ & $.27^{\star \star}$ \\
\hline
\end{tabular}

Note: ${ }^{*}=p<.05 ; * *=p<.01$

Positive correlations between all psychological well-being subscales and all attribution patterns were observed except in the case of personal growth and language policy. Environmental mastery had the highest correlation with Emotion ( $r=$ $.51, p<.01)$ and the least correlation with Language policy ( $r=.21, p<.05)$. Personal growth had the highest correlation with Emotion $(r=.32, p<.01)$ and the least correlation with Intrinsic motivation $(r=.27, p<.05)$. Purpose in life had the 
highest correlation with both Self-image $(r=.41, p<.01)$ and Intrinsic motivation $(r=.41, p<.01)$, and the least correlation with Language policy $(r=.23, p<.05)$. Self-acceptance had the highest correlation with Intrinsic motivation $(r=.34, p<.01)$ and the least correlation with Language policy $(r=.23, p<.05)$. Positive relation had the highest correlation with Selfimage $(r=.43, p<.01)$ and the least correlation with Language policy $(r=.23, p<.05)$. Positive relation had the highest correlation with Intrinsic motivation $(r=.53, p<.01)$ and the least correlation with Language policy $(r=.27, p<.01)$. Results of the correlation indicated that all the subscales of psychological well-being had the least correlation with Language policy subscale of attribution patterns. Moreover, three of the psychological well-being subscales had the highest correlation with Intrinsic motivation subscale of attribution patterns.

To examine the predictability of the attribution patterns by the psychological well-being a series of multiple regression analyses were done.

First, the predictability of the emotion subscale by the psychological well-being subscales was examined. Emotion was entered as dependent variable and the six psychological well-being subscales were entered as independent variables. As can be seen in Table 3, psychological well-being accounted for $29 \%$ of variance in Emotion $[F(6,85)=$ 7.27, $\mathrm{p}<.001]$.

Table 3. Regression Analyses Predicting Emotion

\begin{tabular}{|l|c|c|c|c|c|}
\hline predictor & $\mathrm{R}$ & $\mathrm{R}^{2}$ & Adjusted $\mathrm{R}^{2}$ & $\mathrm{~F}$ & $\mathrm{P}$ \\
\hline psychological well being & $.583^{\mathrm{a}}$ & .339 & .293 & 7.279 & $.000^{\mathrm{a}}$ \\
\hline
\end{tabular}

To examine which subscales predict Emotion, coefficients table was taken into account (Table 4). As Table 4 indicates, only two subscales are significant predictors of Emotion. Environmental mastery $(\beta=.50, t=4.10, p<.001)$ and Positive relation $(\beta=.31, t=2.33, p<.05)$ were the two positive and significant predictors of emotion. Therefore, Environmental mastery was the strongest predictor of Emotion.

Table 4. Coefficients for Predictors of Emotion

\begin{tabular}{|l|c|c|c|c|c|}
\hline \multirow{2}{*}{ Model } & \multicolumn{2}{|c|}{ Unstandardized Coefficients } & Standardized Coefficients & \multirow{2}{*}{$\mathrm{t}$} & \multirow{2}{*}{ Sig. } \\
\cline { 2 - 5 } & $\mathrm{B}$ & Std. Error & Beta & & -.922 \\
\hline (Constant) & -5.798 & 6.288 & & .359 \\
\hline environmental.mastery & .645 & .157 & .505 & 4.105 & .000 \\
\hline Personal.growth & -.084 & .181 & -.053 & -.463 & .645 \\
\hline Purpose.in.life & .138 & .149 & .113 & .930 & .355 \\
\hline Selfacceptance & .009 & .152 & .006 & .060 & .952 \\
\hline Positive.relation & .409 & .175 & .316 & 2.334 & .022 \\
\hline Autonomy & -.321 & .196 & -.233 & -1.634 & .106 \\
\hline
\end{tabular}

Second, the predictability of the Self-image subscale by the psychological well-being subscales was examined. As can be seen in Table 5, psychological well-being accounted for $23 \%$ of variance in Self-image $[F(6,85)=5.62, p<.001]$.

Table 5. Regression Analyses Predicting Self-image

\begin{tabular}{|l|c|c|c|c|c|}
\hline predictor & $\mathrm{R}$ & $\mathrm{R}^{2}$ & Adjusted $\mathrm{R}^{2}$ & $\mathrm{~F}$ & $\mathrm{P}$ \\
\hline psychological well being & $.533^{\mathrm{a}}$ & .284 & .234 & 5.629 & $.000^{\mathrm{a}}$ \\
\hline
\end{tabular}

Coefficients table (table 6$)$ indicates only Environmental mastery $(\beta=.29, t=2.13, p<.05)$ was a positive and significant predictor of Self-image. 
Table 6. Coefficients for Predictors of Self-image

\begin{tabular}{|c|c|c|c|c|c|}
\hline \multirow{2}{*}{ Model } & \multicolumn{2}{|c|}{ Unstandardized Coefficients } & \multirow{2}{*}{$\frac{\text { Standardized Coefficients }}{\text { Beta }}$} & \multirow{2}{*}{$\mathrm{t}$} & \multirow{2}{*}{ Sig. } \\
\hline & $B$ & Std. Error & & & \\
\hline (Constant) & 10.695 & 6.626 & & 1.614 & 110 \\
\hline Environmental.mastery & .303 & .166 & 294 & 2.131 & .041 \\
\hline Personal.growth & -.117 & 191 & -.073 & -.613 & .541 \\
\hline Purpose.in.life & .163 & .157 & .132 & 1.037 & .302 \\
\hline Selfacceptance & .099 & .160 & .069 & .621 & .537 \\
\hline Positive.relation & .291 & .185 & 222 & 1.578 & .118 \\
\hline Autonomy & .101 & 207 & .072 & .487 & .628 \\
\hline
\end{tabular}

Third, the predictability of the Intrinsic motivation subscale by the psychological well-being subscales was examined. As can be seen in Table 7, psychological well-being accounted for $26 \%$ of variance in Intrinsic motivation $[F(6,85)=6.59$, $p<.001]$.

Table 7. Regression Analyses Predicting Intrinsic Motivation

\begin{tabular}{|l|c|c|c|c|c|}
\hline predictor & $\mathrm{R}$ & $\mathrm{R}^{2}$ & Adjusted $\mathrm{R}^{2}$ & $\mathrm{~F}$ & $\mathrm{P}$ \\
\hline psychological well being & $.564^{\mathrm{a}}$ & .318 & .269 & 6.593 & $.000^{\mathrm{a}}$ \\
\hline
\end{tabular}

As coefficients table (Table 8) indicates, only Autonomy $(\beta=.46, t=3.17, p<.01)$ was a positive and significant predictor of Intrinsic motivation.

Table 8. Coefficients for Predictors of Intrinsic Motivation

\begin{tabular}{|c|c|c|c|c|c|}
\hline \multirow{2}{*}{ Model } & \multicolumn{2}{|c|}{ Unstandardized Coefficients } & \multirow{2}{*}{$\frac{\text { Standardijzed Coefficients }}{\text { Beta }}$} & \multirow{2}{*}{$\mathrm{t}$} & \multirow{2}{*}{ Sig. } \\
\hline & $\mathrm{B}$ & Std. Error & & & \\
\hline (Constant) & 7.923 & 2.739 & & 2.893 & .005 \\
\hline environmental.mastery & -.017 & .068 & -.030 & -.242 & .809 \\
\hline Personal.growth & .000 & .079 & .000 & -.004 & 997 \\
\hline Purpose.in.life & .077 & .065 & .147 & 1.187 & 239 \\
\hline Selfacceptance & .069 & .066 & .113 & 1.046 & 298 \\
\hline Positive.relation & -.028 & .076 & -.051 & -.370 & .712 \\
\hline Autonomy & .272 & .085 & .460 & 3.177 & .002 \\
\hline
\end{tabular}

Finally, the predictability of the Language policy subscale by the psychological well-being subscales was examined. As can be seen in Table 9, psychological well-being accounted for $4 \%$ of variance in Language policy which is not statistically significant $[F(6,85)=1.72, p>.05]$. In other words, psychological well-being does not predict language Policy subscale of attribution.

Table 9. Regression Analyses Predicting Language Policy

\begin{tabular}{|l|c|c|c|c|c|}
\hline predictor & $\mathrm{R}$ & $\mathrm{R}^{2}$ & Adjusted $\mathrm{R}^{2}$ & $\mathrm{~F}$ & $\mathrm{P}$ \\
\hline psychological well being & $.329^{\mathrm{a}}$ & .108 & .045 & 1.721 & $.126^{\mathrm{a}}$ \\
\hline
\end{tabular}

\section{Discussion}

One of the aims of this study was first to find significant relationships between university EFL learners' level of psychological well-being and their attributional patterns, and the other was to see if EFL learners' psychological wellbeing can predict their attributional factors.

Regarding the first aim, correlational study showed that Emotion correlated positively and significantly with all the subscales of psychological well-being: Environmental mastery, Personal growth, Purpose in life, Self-acceptance, 
Positive relation and Autonomy. According to Weiner (2000), from attributional approach happiness, frustration, hope, fear, pride, anger, pity, gratitude and shame are the common human emotions. Moreover, from psychological well-being approach a happy person has low degrees of fear, guilt, tension, anger and hostility and is rather optimistic and worryfree (Waterman, 1993; Michalos, 1991; Ryff, 1989). Learners with appropriate state of psychological well-being could be considered as a happy person who would attribute their success or failure to the attribution factor of Emotion. Self image also has significant and positive correlation with all psychological well being subscales. Self image refers to learners' attitudes to their own sense of competence, personal control and capabilities. Michalos (1991) suggested that high scorers in all subcategories of psychological well-being have high degrees of self-esteem and they are emotionally stable. Moreover, they have self-knowledge and awareness (Keyes, 2007). Intrinsically motivated learners tend to work hard and make effort to improve themselves with the help of their own interior reasons. A positive psychological wellbeing approach shows high degrees of energy, vitality and activity in the learners. They have an active life with meaningful work and they are well-directed (Michalos, 1991). Moreover, they develop their thoughts and codes of behavior based on their own personal standards despite the social pressure (Keyes, Shmotkin \& Ryff, 2002). This result is also in line with some other studies which reported the positive association of progression of the learners toward the achievement of personal aims (Tofi, Flett \& Timuthorpe, 1996). The last factor of attribution theory is Language policy which had positive correlation with all the psychological well-being subscales except personal growth. In fact, it was the only non-significant correlation between psychological well-being subscales and attribution patterns. Language policy is the external factor which refers to the teaching methods, educational system and material. Contrary to the other three factors the learners do not have any control over this one.

Regarding the second aim, the results of Regression analyses demonstrated that Language policy could not be predicted by any of psychological well-being subscales. However Environmental mastery and Positive relation could predict the learners' attribution to Emotion. Those learners with higher scores of Positive relations are those who can develop and maintain warm relationship with other people (Keyes, Shmotkin \& Ryff, 2002). They are empathizing, caring and trusting (Ryff, 1998). They have strong capability of empathy and affection; therefore, they are stable in their emotions and experiencing positive feelings and attributing to a factor which could lead to success in their learning. Environmental mastery refers to those learners who can take the opportunities in learning environment to meet their personal needs. They feel they can improve the context in which they are studying (Jale Eldeleklioglua, Aynur Yilmaz, Filiz Gültekin, 2010). This psychological well-being subscale could be a good predictor for both attributional factors of Emotion and Self-image. Those learners who are high scorers in Environmental mastery are experiencing positive and strong feelings and emotions in the process of learning (Kayla Cripps \& Brett Zyromski, 2009) and they have positive Self-image as they see themselves capable of creating surrounding contexts of learning suitable to their own values. The third predictor is Autonomy which could predict the learners' attribution to intrinsic motivation. Those learners who had high scores in this subscale of psychological well-being try hard to keep their individuality in any social environment. In spite of outside pressure they keep their personal standards as the basis of their own thoughts, views and attitudes (Ryff, 1989). Their own reason of learning not the external force is their motivation to achieve what they attempt to achieve.

Raising awareness in language teachers and learners could be the primary implication of this study. Teachers could help the learners to get more familiar with their personal differences and the effect of these differences on their attributional reasons in learning process. Knowing about the state of their psychological well-being, learners could make better choices and make directed attempts toward better attitudes in case of success or failure. Conscientious raising in learners about the factors which cause the right or wrong attribution could be essential for their future endeavors in any area of their life. As the other implication, using the results of this study and the like in the process of reattribution could provide different viewpoints for the experts to have a better control over learners' inappropriate attributions.

Many factors could affect learners' attribution in their learning process; therefore, more investigation and studies related to the same topic could be helpful. Including more variables such as family background, gender difference, culture, social class, learning styles, EQ and IQ could provide more accurate and significant or even different results. The same study can be replicated in different settings, various age groups and learners with different proficiency levels. Future studies can also examine the effect of the relationship between these two variables on subjects' achievement and level of proficiency.

\section{References}

Bandura, A. (1977). Social learning theory. Englewood Cliffs, NJ: Prentice Hall.

Beyer, S. $(1998,1999)$. Gender differences in causal attributions by college students of performance on course examinations. Current Psychology: Developmental, Learning, Personality, Social, 17 (4), 346-358. http://dx.doi.org/10.1007/s12144-998-1016-5 
Brown, D. R. (1992). Physical activity, aging, and psychological well-being: An overview of the research. Canadian Journal of Sport Sciences, 17(3), 185-193.

Conway, C., \& MacLeod, A. K. (2002). Well-being: Its importance in clinical research and practice. Clinical Psychology, 16, 26-29.

Dörnyei, Z. (2005). The psychology of the language learner individual differences in second language acquisition. New Jersey: Lawrence Elbaum Associates.

Erikson, E. H. (Ed.). (1963). Youth: Change and challenge. Basic books.

Heider, F. (1958). The Psychology of Interpersonal Relations. New York: Wiley.

Hsieh, P. H., \& Schallert, D. L. (2008). Implications from self-efficacy and attribution theories for an understanding of undergraduates' motivation in a foreign language course. Contemporary Educational Psychology, 33, 513-532.

Jones, L. (2002). Adolescent understandings of political violence. A qualitative study. Social Science \& Medicine, 55, 1351-1371.

Keyes, C. (2007). Promoting and Protecting Mental Health as Flourishing: A Complementary Strategy for Improving National Mental Health. American Psychologist, 62 (2), 95-108.

Lavasani M.G., Borhanzadeh S., Afzali L., \& Hejazi E. (2011). The relationship between perceived parenting styles and social support with psychological well-being. Procedia Soc Behav Sci, 15, 1852-1856.

Liebkind, K. \& Jasinskaja-Lathi, I. (2000). Acculturation and Psychological Well-Being among Immigrant Adolescents in Finland: A Comparative Study of Adolescents from Different Cultural Backgrounds. Journal of Adolescent Research, 15, 446- 469. DOI: $10.1177 / 0743558400154002$

Lim, H. (2007). Effects of attributions and task values on foreign language use anxiety. Journal of Education and Human Development, 1(2), 1-20.

Marsh, H. W., \& Craven, R. G. (2006). Reciprocal effects of self-concept and performance from a multidimensional perspective: Beyond seductive pleasure and unidimensional perspectives. Perspectives on Psychological Science, 1, 95-180.

Meece, J. L., Glienke, B. B.Samantha, \& Burg, S. (2006). Gender and motivation. Journal of School Psychology 44, 351-373. http://dx.doi.org/10.1016/j.jsp.2006.04.004

O'Reilly, A., Ryan, D., \& Hickey, T. (2010). The psychological well-being and sociocultural adaptation of short-term international students in Ireland. Journal of College Student Development, 51(5), 584-598. doi:http://dx.doi.org/10.1353/csd.2010.0011

Parto, M., \& Besharat, M. A. (2011). Mindfulness, Psychological Well-Being and Psychological Distress in Adolescents: Assessing the Mediating Variables and Mechanisms of Autonomy and Self-Regulation. Social and Behavioral Sciences, 30, 578-582. DOI: 10.1016/j.sbspro.2011.10.112.

Pishghadam, R., \& Modarresi, G. (2008). The construct validation and application of questionnaire of attribution theory for foreign language learners. Iranian Journal of Language Studies, 2(3), 299-324.

Pishghadam, R., \& Motakef, R. (2011). Attributional patterns with respect to major and attendance in private language schools: A case of EFL context. Theory and Practice in Language Studies, 1(7), 888-894. http://dx.doi.org/10.4304/tpls.1.7.888-894

Pishghadam, R., \& Zabihi, R. (2011). Foreign language attributions and achievement in foreign language classes. International Journal of Linguistics, 3(1), 1-11.

Prilleltensky, I. \& Prilleltensky, O. (2006) Promoting well-being: Linking personal, organizational, and community change._John Wiley and Sons, Hoboken, NJ.

Rotter, J. B. (1966). Generalized expectancies for internal versus external control of reinforcement: Psychological Monographs: General \& Applied 80(1) 1966, 1-28.

Sedaghat, M., Mohammadi, R., Alizadeh, K., \& Hosein, I. A. (2011). The Effect of Mindfulness-Based Stress Reduction on Mindfulness, Stress Level, Psychological and Emotional Well-Being in Iranian Sample. Procedia-Social and Behavioral Sciences, 30, 929934.

Souri, H., \& Hasanirad, T. (2011). Relationship between Resilience, Optimism and Psychological Well-being in Students of Medicine, Procedia. Social and Behavioral Sciences, 30, 1541-1544.

Van Dierendonck, D. (2004). The construct validity of Ryff's Scales of Psychological Well-being and its extension with spiritual wellbeing. Personality and individual differences 36 (3), 629-643.

Vleioras, G., \& Bosma, H.A. (2005). Are identity styles important for psychological well-being? Journal of Adolescence, 28(3), 397-409.

Weiner, B. (1974). Motivational psychology and educational research. Educational Psychologist, 11 (2), 96-101. http://dx.doi.org/10.1080/00461527409529130

Weiner, B. (1979). A theory of motivation for some classroom experiences. Journal of Psychology, 71, 3-25.

Weiner, B. (2000). Interpersonal and interpersonal theories of motivation from an attributional perspective. Educational Psychology Review, 12(1), 1-14. http://dx.doi.org/10.1023/A:1009017532121

Weiner, I. B., \& Craighead, W. E. (2010). Attribution theory. The Corsini Encyclopedia of Psychology, Vol. 1, (4th ed), (pp. 184-186). New Jersey: John Wiley \& Sons.

White, R. W. (1959). Motivation reconsidered: The concept of competence. Psychological Review, 66(5), 297333.http://dx.doi.org/10.1037/h0040934

Williams, M., \& Burden, R. L. (1997). Psychology for language teachers: A social constructivist approach. Cambridge: Cambridge University Press.

Williams, M., Burden, R., \& Al-Baharna, S. (2001). Making sense of success and failure: The role of the individual in motivation theory. In Z. Dörnyei, \& R. Schmidt (Eds.), Motivation and second language acquisition (pp. 171-184). Honolulu: University of Hawaii, Second Language Teaching and Curriculum Center. 
Williams, M., Burden, R., Poulet, G., \& Maun, I. (2004). Learners' perceptions of their success and failure s in foreign language learning. Language Learning Journal, 30, 19-29. http://dx.doi.org/10.1080/09571730485200191

Wu, J. (2011). An investigation and analysis of attribution preference and gender difference of non-English majors' English learningbased on investigation of non-English majors in Tianjin Polytechnic University. Journal of Language Teaching and Research, 2(2), 332-337. http://dx.doi.org/10.4304/jttr.2.2.332-337. 